\title{
Repercussões da alergia ao leite de vaca sob a ótica materna
}

\author{
Repercussions of cow's milk allergy from the perspective of mothers
}

Como citar este artigo:

Reis P, Marcon SS, Batista VC, Marquete VF, Nass EMA, Ferreira PC, Ichisato SMT. Repercussions of cow's milk allergy from the perspective of mothers. Rev Rene. 2020;21:e42929. DOI: https://doi.org/10.15253/2175-6783.20202142929

(D) Pamela dos Reis ${ }^{1}$
(D) Sonia Silva Marcon ${ }^{1}$
(D) Vanessa Carla Batista ${ }^{1}$
(D) Verônica Francisqueti Marquete ${ }^{1}$
(D) Evelin Matilde Arcai Nass ${ }^{1}$
(D) Patrícia Chatalov Ferreira ${ }^{1}$
(D) Sueli Mutsumi Tsukuda Ichisato ${ }^{1}$

${ }^{1}$ Universidade Estadual de Maringá. Maringá, PR, Brasil.

\section{Autor correspondente: \\ Pamela dos Reis \\ Universidade Estadual de Maringá. \\ Av. Colombo, 5.920, Jd. Universitário. \\ CEP: 87020-900. Maringá, PR, Brasil. \\ E-mail: pamdosreis@gmail.com}

\begin{abstract}
RESUMO
Objetivo: compreender as repercussões da alergia à proteína do leite de vaca, sob a ótica materna. Métodos: estudo qualitativo, realizado com nove mães, as quais foram localizadas em grupos do Facebook. Dados coletados por meio de entrevistas semiestruturadas e submetidos à análise de conteúdo. Resultados: emergiram três categorias: Convivendo com o despreparo dos profissionais e serviços para diagnóstico e tratamento da alergia à proteína ao leite de vaca; Afastamento social: resultado do medo e da incompreensão; e A mãe no centro do cuidado. Conclusão: a rigorosa restrição alimentar, decorrente da alergia à proteína do leite de vaca, repercute significativamente na vida de crianças e famílias, em especial das mães, desencadeando isolamento social da família e insegurança na utilização de serviços de saúde e educação, devido ao desconhecimento e despreparo de profissionais.

Descritores: Hipersensibilidade a Leite; Saúde Materno-Infantil; Apoio Social; Aleitamento Materno; Dieta.
\end{abstract}

\section{ABSTRACT}

Objective: understanding the repercussions of cow's milk allergy from the perspective of mothers. Methods: qualitative study, carried out with nine mothers who were found in Facebook groups. Data was collected through semi-structured interviews and submitted to content analysis. Results: three categories emerged: living with the unpreparedness of health services and professionals to diagnose and treat allergies to cow's milk protein; social isolation: the result of fear and misunderstanding; and the mother as the central figure of care. Conclusion: the rigorous alimentary restriction that results from allergies to the protein in cow's milk significantly reverberates in the lives of children and families, especially mothers, leading to the social isolation of the family and to insecurity in the use of health and education services, due to the lack of knowledge and preparation of the professionals.

Descriptors: Milk Hypersensitivity; Maternal and Child Health; Social Support; Breast Feeding; Diet. 


\section{Introdução}

Nas últimas décadas, observa-se crescente ocorrência de reações alérgicas a alimentos, sendo possível afirmar que a alergia alimentar é um problema nutricional contemporâneo e em ascensão ${ }^{(1)}$. Esse tipo de alergia resulta de resposta imunológica específica e reprodutível da exposição a determinado antígeno alimentar, geralmente uma proteína, associada a uma resposta imunitária hipersensível ${ }^{(2)}$.

Qualquer alimento pode causar alergia alimentar, porém, em lactentes e crianças pequenas, o leite de vaca é o principal responsável. Estudo realizado em serviços públicos, de atenção nutricional, de 34 municípios brasileiros, constatou prevalência de 0,4\% de Alergia à Proteína do Leite de Vaca (APLV) ${ }^{(3)}$. Entretanto, estimar a prevalência deste tipo de alergia é difícil pela própria história natural, visto que a taxa de resolução é relativamente alta após a primeira infância. Também pode haver diminuição da alergenicidade, quando o leite é submetido ao cozimento, pois este processo provoca alteração em algumas das proteínas. Ademais, reações ao leite de vaca não relacionadas ao sistema imunológico, como a intolerância à lactose, podem acarretar superestimação de sua prevalência nos estudos de autorrelato ${ }^{(4)}$.

A alergia à proteína do leite de vaca pode desencadear sintomas diversos, dependendo do mecanismo imunológico envolvido. A maioria das reações ocorre logo após a ingestão, devido à produção excessiva de imunoglobulina E (IgE) para determinado alimento. Estas reações podem atingir pele e/ou mucosas, vias respiratórias e os sistemas gastrintestinal e cardiovascular, de forma isolada ou combinada. Em outros casos, as manifestações podem ser tardias, mediadas por células (linfócitos e eosinófilos), que acometem com maior frequência a pele e tubo digestivo ${ }^{(2,5)}$. Em casos graves, quantidades mínimas de leite podem induzir reações fatais, no período de 30 minutos a duas horas $^{(2)}$. Algumas crianças apresentam reação por inalação ou contato do alérgeno com a pele $\mathrm{e}^{(2,5)}$.

As manifestações alérgicas da alergia à proteí- na do leite de vaca começam nos primeiros meses ou dias de vida e, na maioria dos casos, é uma condição transitória, que dificilmente persiste além do segundo ano de vida ${ }^{(5)}$. 0 tratamento é centrado na dieta de exclusão total de leite de vaca e derivados, alimentos com traços e, em alguns casos, na imunoterapia oral ${ }^{(6)}$. A ingestão acidental pode ocorrer por contaminação, durante o processamento industrial dos alimentos, ou ainda, pelo consumo de produtos que contêm leite de vaca com outra nomenclatura, o que dificulta a identificação $0^{(2,5)}$.

Independentemente da gravidade da reação, esta condição implica necessidade maior de cuidados com a saúde, em especial com a alimentação da criança, acarretando maior dedicação e atenção por parte das mães que, na maioria das vezes, são responsáveis pelos cuidados às crianças ${ }^{(7-8)}$.

Ao considerar esse contexto, é lícito afirmar que a repercussão experienciada pela primeira autora deste estudo, quando se deparou com a realidade de ser mãe de criança com Alergia à Proteína do Leite de Vaca, e o desconhecimento da população em geral e dos próprios profissionais de saúde, resultando em insegurança e horas de busca por informações, constituíram os motivos desencadeadores do interesse em realizar o presente estudo.

Dessa forma, com intuito de produzir estudo que retratasse tal situação na perspectiva materna e fornecer subsídios para o manejo da enfermagem na assistência à família e às crianças com APLV, surgiu o questionamento: quais implicações a alergia à proteína do leite de vaca trazem à vida de crianças acometidas e às respectivas famílias, em especial às mães, principais cuidadoras? Para respondê-lo, definiu-se como objetivo do estudo: compreender as repercussões da alergia à proteína do leite de vaca, sob a ótica materna.

\section{Métodos}

Trata-se de estudo qualitativo, realizado em município de médio porte, na Região Sul do Brasil, 
com mães participantes de grupos on-line sobre alergia à proteína do leite de vaca, na rede social Facebook. Os grupos foram explorados por uma das pesquisadoras, que buscou mães que disponibilizavam de forma pública, em perfil, a informação de residência no município do estudo. Posteriormente, por meio de mensagem privada, na própria rede social, convidou as mães identificadas para participarem do estudo e agendou as entrevistas.

Definiu-se como critérios de inclusão ser mãe com idade igual ou superior a 18 anos, ter filho(s) com alergia à proteína do leite de vaca e residir no município do estudo. Foram identificadas 19 mães residentes no município e todas foram convidadas a participarem do estudo. As pesquisadoras não conheciam nenhuma destas mães. Contudo, das 19, quatro não visualizaram a mensagem, uma visualizou, mas não respondeu, três relataram que os filhos tinham intolerância à lactose e duas haviam mudado de município. Portanto, o número de participantes foi definido por exaustão, pois as nove que responderam às mensagens e atenderam aos critérios previamente estabelecidos foram incluídas. Este número possibilitou a aproximação ao objeto e identificação de temas comuns, que permitiram que se alcançasse o objetivo do estudo.

Os dados foram coletados de janeiro a março de 2017, mediante entrevistas semiestruturadas, realizadas pelas duas primeiras autoras, nos domicílios das participantes, exceto um caso, em que a participante optou pelo local de trabalho. Utilizou-se de roteiro semiestruturado, abordando características socioeconômicas (idade, escolaridade e renda familiar) e as seguintes questões norteadoras: fale-me sobre sua experiência como mãe de criança com Alergia à Proteína do Leite de Vaca? 0 que tem facilitado ou dificultado esta experiência? O que lhe ajudou a enfrentar esta condição? As entrevistas foram áudio gravadas, após consentimento, e tiveram duração média de 40 minutos, sendo, posteriormente, transcritas na íntegra, preferencialmente no mesmo dia da realização. 0 material transcrito não foi retornado às participantes para complementação e/ou correções.
Os dados foram submetidos à Análise de Conteúdo, modalidade temática, seguindo as três etapas propostas $^{(9)}$. Na pré-análise, realizou-se leitura flutuante de todo o material, com constituição do corpus de análise. Na exploração do material, considerou-se os critérios de exaustividade, representatividade, homogeneidade e pertinência para identificação das unidades de registro. Por fim, na etapa de tratamento dos resultados procedeu-se a sínteses das falas e, por meio da compreensão, identificou-se os núcleos de sentido e a concepção de categorias.

Adotou-se como referencial a Teoria dos Sistemas Familiares, adaptação da teoria geral dos sistemas, que considera a família um sistema no qual os membros são unidades singulares com comportamentos distintos que se complementam e interagem constantemente, a fim de atingir a um objetivo. Apesar da interdependência que compõem esse todo, para a sua compreensão, é fundamental considerar as partes, ponderando que a conduta e experiência de cada membro do núcleo familiar irão influenciar e afetar todo o sistema ${ }^{(10)}$. Desta forma, o sistema familiar vive em constate construção e reconstrução, objetivando sempre o bom convívio e equilíbrio frente às desestabilizações, como, no caso, o adoecimento de um dos entes. Quando a Teoria dos Sistemas Familiares é empregada à enfermagem, é possível observar a família como uma unidade de cuidado, proporcionando assistência mais humana, holística e resolutiva ${ }^{(10)}$.

O projeto foi aprovado pelo Comitê de Ética em Pesquisa com Seres Humanos da instituição signatária (parecer $n^{\circ} 1.868 .933 / 2016$ ). As participantes assinaram o Termo de Consentimento Livre e Esclarecido e, para garantir-lhes o anonimato, na apresentação dos resultados, os extratos dos relatos estão identificados pela letra M (mãe), seguida do número da ordem de realização das entrevistas.

\section{Resultados}

A idade das participantes variou de 26 a 49 anos. Duas mães concluíram o ensino médio e as de- 
mais o ensino superior, com renda familiar de três a 15 salários mínimos. 0 tempo de aleitamento materno variou de cinco a 26 meses. Sete mulheres amamentaram os filhos por mais de um ano, sendo que quatro delas ainda estavam amamentando por ocasião da entrevista. Uma participante fazia o acompanhamento de saúde do filho pelo Sistema Único de Saúde e as demais utilizavam convênios privados. Da análise dos dados, emergiram três categorias: Convivendo com o despreparo dos profissionais e serviços para diagnóstico e tratamento da alergia à proteína ao leite de vaca; Afastamento social: resultado do medo e da incompreensão; e A mãe no centro do cuidado.

\section{Convivendo com o despreparo dos profissionais e serviços para diagnóstico e tratamento da alergia à proteína ao leite de vaca}

0 frequente descaso às informações dadas pelas mães, associado a orientações superficiais, sem embasamento e comprovação científica, em muitos casos enfraqueceram a relação de confiança necessária entre profissionais de saúde e mães das crianças com esta alergia. Ela chorava demais, porque sentia dor, não dormia, e os pediatras achavam que era porque eu sou mãe de primeira viagem, que estava exagerando. Passei por cinco pediatras até ser diagnosticada (M9). Tirando a médica alergologista e a gastroenterologista, a abordagem dos outros profissionais da saúde são sempre superficiais, quase não sabem sobre o assunto e nos tratam como ignorantes exageradas (M1).

0 desconhecimento dos profissionais sobre a condição foi considerado agravante pelas mães, que relataram a indicação equivocada de tratamentos. Um pediatra disse: "mas mãe, é zero lactose, esse leite pode dar". Eles não sabem a diferença entre alergia à proteína do leite de vaca e intolerância à lactose. Nós temos que correr atráse acreditar no nosso sexto sentido (M3). Alguns profissionais confundiam com intolerância à lactose. Até encontrar a médica que realmente entendia do assunto, passamos por várias pediatras (M6).

O uso de medicamentos e vacinas exigiu atenção redobrada por parte das mães, pois estes podem conter traços de leite em suas fórmulas e, ainda assim, serem prescritos/ indicados às crianças. Quando for dar remédio, tem que prestar muita atenção, se não tem traços na fórmula. Precisamos divulgar mais o assunto, explicar a gravidade da ingestão, nas campanhas de vacinação, deixar claro que algumas vacinas têm traços de leite (M3). Aos dois meses, após tomar as vacinas, começou a apresentar fios de sangue nas fezes. Suspeitamos que podia seralergia à vacina [componentes com leite], e era (M1).

Uma vez estabelecidos o diagnóstico e o tratamento, outra preocupação surgia: o despreparo das instituições de educação infantil, o que motivou algumas mães a postergaram o ingresso dos filhos nas escolas. Tenho medo, tanto que ainda não pus na escola (M2). A escola sabe da alergia, sabe das restrições, porém não trata com seriedade, não são preparados para isso(M1). Na escola, alguns profissionais acham que estou exagerando (M8).

Destarte, os relatos desta categoria mostraram que as famílias vivenciavam dificuldades por não encontrarem profissionais da área da saúde e educação preparados para ofertar os cuidados necessários a esse grupo de crianças.

\section{Afastamento social: resultado do medo e da incompreensão}

A alergia alimentar apresentou efeito significativo na vida familiar, especialmente da criança e respectiva mãe, visto que dificultou o viver em sociedade, trazendo restrições que afetaram o relacionamento com amigos e a interação com a família extensa. Ademais, a exigência de cuidados para evitar a exposição da criança ao alérgeno, acompanha o medo de possível reação alérgica, gerando momentos de preocupação e até mesmo constrangimento às mães. É preciso ter cuidados com toque, beijos, alimentação, leitura de rótulos, cosméticos, que todos da família e os mais próximos usam, para que não contenha leite ou alguma das proteínas na composição (M1). Tinha lugares que eu evitava levar ele, para não repararem, então acabava não indo ninguém lá de casa. Porque é chato. Eu ficava toda a hora dizendo para as pessoas: lava a mão, lava a boca, não pode pegar(M7).

Os cuidados se modificam com o crescimento das crianças. Isto porque, enquanto bebês, as mães relataram ter controle sobre o que é ingerido e ofertado aos filhos, por outras pessoas. Porém, quando as crianças passam a se alimentar sozinhas, o desejo e a curiosidade por novos sabores podem resultar em episódios mais frequentes de exposição ao alérgeno e/ou frustração da criança pela extensa e rigorosa limitação alimentar. Para minimizar estes aspectos, há tendência de ocorrer maior afastamento do convívio social. Isolar um bebê é fácil, porém ele cresce, os amiguinhos oferecem... eles passam a ter vontades (M3). As festas são sempre um grande desafio, pois ele fica triste ao 
perceberquenão pode comernada. Daídá aquela angústia de tervontade de "colocar numa bolha"(M8). Outra dificuldade foi quando ele começou a entender as festinhas. Ele via as pessoas comendo e queria. Todo lugar eu tinha que disfarçar para ele não ver e comer. Eu sempre levava uma barrinha de chocolate de soja para ele, que era como se fosse um prêmio de consolação (M7).

É notório que as dificuldades nos cuidados da criança com este tipo de alergia podem afetar o núcleo familiar, de forma que atividades de lazer, essenciais para interação familiar e social, como viagens ou alimentar-se fora do domicílio, passam a ocorrer de forma limitada. O ruiméessa parte social, que todo alérgico alimentar sofre, porque o pessoal se reúne para ir a uma pizzaria e você não pode, a gente praticamente não tem o que comer fora (M9). Esses dias não pude fazer almoço em casa, então fomos a um restaurante. Não tinha um prato fora o arroz e feijão que ele podia comer... todos os outros eram feitos com creme de leite, legumes everduras refogados na manteiga, a chapa onde fazem a carne, eles fritam queijo (M3).

De acordo com as mães, os cuidados com a criança com este tipo de alergia são, muitas vezes, considerados por outras pessoas como exagerados. Para grande parte das participantes, a incompreensão de parentes e amigos quanto à gravidade da alergia resultou em desconforto nas relações Sociais. Não é fácil ser mãe de bebê alérgico num mundo onde só se entende essa alergia quem a vive. Muitos acham que éfrescura, muitos "dei só um pedacinho"(M3). Muitas vezes fui chamada de superprotetora (M6). Somos taxadas de exageradas, que um beijo após a ingestão de alguma proteína não irá causar nada (M1). O povo achava assim: "nossa, que neurótica! Nãoétudo isso". Inclusive minha mãe, meu pai, pessoas mais velhas. Falavam: "Nossa! Não pode encostar". Foi maisfácil nos afastarmos [núcleo familiar] de algumas situações (M7).

Apreendeu-se que alergia à proteína do leite de vaca desencadeia a convivência com incompreensão social sobre a própria condição e os cuidados necessários, o que contribui para o isolamento social da criança e de cuidadores, o que pode interferir na vida da família como um todo.

\section{A mãe no centro do cuidado}

É natural o senso de responsabilidade materno em relação aos cuidados com os filhos. Entretanto, a intensa preocupação com a exposição dos filhos às proteínas do leite de vaca coloca as mães no centro do cuidado, inclusive, muitas relataram se privar dos próprios prazeres. A exemplo, a manutenção do aleitamento materno, mesmo em casos de crianças extremamente sensíveis a traços de leite de vaca, que podem estar presentes na alimentação da mãe e passar para o leite. Nestes casos, faz-se necessária dieta isenta de leite de vaca e traços também pela nutriz. Por mais que eи quisesse amamentar, achei que ia enlouquecer. Achei que não existia vida sem as coisas que eu comia. No começo, fiquei bem mal. Mas, para cuidar dela [filha], faço tudo (M2). As maiores dificuldades ocorrem quando preciso me alimentar fora de casa, pois são poucos os lugares com alimentos sem leite e traços (M4).

A dificuldade para adesão à dieta, na maioria das vezes, era decorrente da necessidade de rigoroso cuidado no preparo dos alimentos, devido ao risco de contaminação cruzada, fato desconhecido pela maioria das pessoas. É um desafio as pessoas entenderem que não pode misturar, usar a mesma colher para mexer... Por isso, é praticamente impossível comer em restaurante. A contaminação cruzada é o que as pessoas menos entendem (M9). No início, foi bem dificil ajustar a dieta de exclusão, acabava consumindo traços de leite e ela tinha reação. Passei a comer só o que cozinhava em casa, comia muita fruta e caprichava com muitos legumes e verduras. E, assim, amamentei até dois anos (M6).

À despeito das restrições, algumas mães relataram alívio ao perceberem que, com a implementação de cuidados na própria dieta, diminuíam ou até mesmo cessavam os sinais e sintomas da alergia. Assim, o cuidado aos filhos, por meio do aleitamento materno, apesar das privações pessoais, foi considerado prioridade. Amamentei durante o diagnóstico, quando levei a sério e fiz dieta de exclusão, pararam as reações nela (M1). Foi ótimo perceber que com a minha dieta, os sintomas cessaram, e o bebê estava mamando bem, sem sentir dores (M4).

Em contrapartida, apesar de reconhecerem os inegáveis benefícios do aleitamento materno, algumas não conseguiram mantê-lo. Isto ocorreu devido ao medo de prejudicar a saúde do filho, dificuldade de adaptação da mãe à dieta de exclusão, ou mesmo por falta de orientação sobre o uso deste tipo de dieta e respectivos benefícios. Não conseguia cozinhar a dieta especial para mim, e meu medo de comer algo sem saber que tinha leite e isso prejudicar ele [filho] me fez tomar a decisão de parar de amamentar... A fórmula me pareceu a alternativa mais limpa de traços (M3). Comecei a passar mal com a dieta, pois não conseguia preparar muitas coisas para comer e me sentia muito fraca. Aí, amamentei mais um mês e fui introduzindo aos poucos a fórmula especial(M7).

Nesse cenário, também passaram a conviver com a ausência de incentivo e apoio ao aleitamento materno, inclusive por parte dos profissionais da saúde, que questionavam 
a validade do esforço em relação a este intento. A primeira coisa que você escuta de profissionais mal informados é que tem que parar de amamentar porque seu leite faz mal. Isso é mentira! O que você come pode fazer mal para o filho, não o leite materno. A maioria das mães acha melhor dar a fórmula. Quando o pessoal insistia em me fazer parar de amamentar, eu dizia "você vai compraroleite? Custa 200 reais a lata" e eles se apavoravam. A pessoa não entendia o problema e, principalmente, a importância da amamentação (M2).

Outra preocupação e motivo de cuidados foram os alimentos industrializados, que somente são consumidos por mães em aleitamento materno ou pelas crianças, após minuciosa inspeção do rótulo, o que demanda tempo e paciência. Quando íamos ao mercado, eram horas lendo rótulos, foram muitas ligações e e-mail para as empresas que não descriminavam corretamente os ingredientes nos rótulos dos seus produtos (M6).

Mesmo quando o alérgeno não é utilizado como ingrediente do alimento, existe a possibilidade de presença de traços pelo uso do mesmo maquinário para embalagem ou processamento. A carência de registro nos rótulos sobre a possibilidade de contaminação cruzada torna ineficiente a análise realizada pelas mães, podendo gerar medo e angústia. As empresas que fabricam produtos sem leite deveriam cuidar mais, para que realmente os produtos não contenham traços. Os rótulos deveriam ser mais claros, porque, muitas vezes, vem escrito sem leite, porém dá reação, daí ligamos no SAC [Serviço de Atendimento ao Consumidor] e informam que utilizam o mesmo maquinário de produtos com leite (M3). Ela tomou leite vegetal e teve diarreia, urticária e inchou, fui atrás e descobri que eles envasavam em uma fábrica que envasa leite de vaca. Isso pode dar choque anafilático, entendeu?! (M2).

As mães de crianças com esta alergia experimentam diversidade de sentimentos e dificuldades, por tratar-se de condição, na maioria das vezes, desconhecida. O início dos sintomas até o diagnóstico foi sofrido. Observar que o bebê está com dores e não saber como ajudar é muito difícil (M4). Tudo contribuiu para um estresse muito grande, sofri demais, levando-a para médicos e fazendo exames. Fiquei esgotada, não énada fácil (M9).

Entretanto, ao obterem conhecimento sobre a doença, e principalmente ao verem a melhora clínica das crianças, sentiram-se motivadas para dar seguimento aos cuidados. A paciência foi referida como atributo essencial no enfrentamento deste problema. Tem horas que ficamos muito desanimados, mas tem que ter paciência. É o principal, porque passa, ou pelo menos melhora (M7). Quando se tem consciência do que éa alergia, a mudança ocorre sem sofrimento, pois queremos a cura. Vamos aprendendo a buscar alternativas e viver esse pro- blema da forma mais positiva possivel (M3).

Contudo, é importante destacar que, se por um lado a ausência de apoio e compreensão dificulta o tratamento, 0 suporte de pais eavós das crianças é muito positivo. Minha mãe, pai, marido, deram muito apoio. Minha mãe semprefoi atrás de tudo, meajudando muito (M2). A minha familia sempre foi um apoio, buscando alternativas sem leite para o que eu gosto de comer [mãe com restrição alimentar para manter aleitamento] (M4).

A troca de experiência com outras mães na mesma situação, também, foi considerada benéfica. Conforme os relatos, além da troca de informações sobre a doença e cuidados, a oportunidade de expressar preocupações, angústias e também vitórias contribuiu para a saúde emocional dessas mães. A troca de experiências com as outras mães me ajudou muito. Conversar, desabafar (M5). O que me ajudou muito é que, na sala do meu filho, têm duas mães com filhos alérgicos. Elas foram me dando dicas e me mostrando as saídas para enfrentara situação (M2).

Ademais, a participação em grupos sobre o tema em redes e mídias sociais, como o Facebook® e WhatsApp, foram apontados pelas mães como importante fonte de apoio informacional. Uma amiga que também é mãe de criança alérgica à proteína do leite de vaca me inseriu em grupos de apoio nas redes sociais que fizeram toda a diferença (M6). Eu tenho bastante ajuda com o pessoal do WhatsApp (M5). As redes sociais ajudam a encontrar pessoas que estão passando pela mesma situação, e nesses grupos, a gente encontra ajuda para o nosso emocional, para achar o caminho (M9).

Conclui-se que ter um filho com alergia à proteína do leite de vaca traz sofrimento, exige muito esforço, paciência, privações e cuidados, o que, de certo modo, interfere na vivência de todos os membros da família, embora o processo centralizado na figura materna, que inclusive, muitas vezes, o vivencia de forma solitária.

\section{Discussão}

0 estudo teve como limitação o fato de ter sido desenvolvido com amostra de mães com escolaridade elevada e acesso à assistência privada de saúde. Ainda, a quantidade limitada de participantes e a abordagem qualitativa, que envolve a subjetividade do investigador, não permitem a generalização dos resultados, e também, o fato de as transcrições dos materiais gra- 
vados não terem retornado aos participantes, que ficaram impossibilitados de complementar, corrigir ou mesmo discordar de aspectos afirmados anteriormente.

De qualquer modo, esses aspectos não invalidam os resultados obtidos, pelo contrário, ressaltaram a necessidade de novas pesquisas que tenham como propósito, por exemplo, investigar como mães com baixa escolaridade e condição socioeconômica lidam com a alergia à proteína do leite de vaca. Ademais, em investigações futuras seria interessante o emprego de diferente delineamento metodológico, de modo a explorar novos aspectos do fenômeno.

Os resultados do presente estudo podem contribuir para o ensino, a pesquisa e assistência na área da saúde da criança e família, à medida que aponta insipiência dos profissionais, fragilidades nas condutas destes e dificuldades enfrentadas por mães/famílias de crianças com alergia à proteína do leite de vaca. Para atender às necessidades deste público, faz-se necessário sensibilizar e capacitar os profissionais sobre esta realidade.

Os resultados mostraram que, apesar de a alergia alimentar acometer diretamente apenas o sistema imunológico da criança, a presença da alergia traz implicações para todos os membros do núcleo familiar, sobretudo para as mães, principais cuidadoras. Este fato pode ser compreendido a partir da Teoria dos Sistemas Familiares, segundo a qual a família (todo) é composta por seus membros (partes) que interagem mutuamente para alcançar um objetivo comum, sendo que a experiência de cada membro é influenciada e, ao mesmo tempo, influencia todo o sistema familiar, assim como ocorre com outros subsistemas - parentes, amigos, profissionais de saúde etc. ${ }^{(10)}$.

Os obstáculos em relação à alergia à proteína do leite de vaca são experienciados desde o diagnóstico, pois muitos profissionais desconhecem as particularidades deste agravo. Enfatiza-se que, apenas a alergia mediada por IgE pode ser identificada por exames laboratoriais, o que exclui os casos de alergia mediada por células. Por isso, o teste mais indicado é o de desencadeamento alimentar oral ${ }^{(11)}$, pautado no conhecimento por parte do profissional e relatos maternos. Deste modo, observou-se que as falas das mães corroboraram a necessidade apontada pelos estudos da Associação Brasileira de Alergia e Imunologia, de que os profissionais da rede pública e privada precisam ser capacitados para diagnosticar e tratar este tipo de alergia ${ }^{(12)}$, e serem sensíveis às queixas maternas, pois é a partir delas que se inicia o processo de investigação.

Ao considerar a Teoria dos Sistemas Familiares, levanta-se a necessidade de a equipe de saúde transcender o tratamento para além do agravo em si e do indivíduo com esta condição. Ou seja, a assistência precisa envolver o sistema familiar como um todo, e ao mesmo tempo, ser singular a cada uma de suas partes $^{(10)}$. De acordo com estudo sobre o impacto psicossocial e comportamental da alergia alimentar em crianças, adolescentes e familiares, é preciso considerar que todas as pessoas que mantêm contato mais frequente/próximo com a criança, necessitam de suporte, principalmente informacional. As estratégias de educação nutricional devem englobar a comunidade, incluindo escola e amigos, para que as pessoas do convívio da criança consigam entender a importância da vigilância, com potencial necessidade de tratamento de emergência, contribuindo, ao mesmo tempo, para possibilidade de uma vida social normal ${ }^{(13)}$.

Nessa direção, é valido ponderar que o conhecimento sobre a alergia à proteína do leite de vaca e de outras alergias alimentares, por parte de professores e responsáveis pelos cuidados em escolas infantis, é fundamental e proporciona segurança e tranquilidade aos pais, pois as crianças passam tempo substancial nestes espaços ${ }^{(13)}$. Inclusive, o despreparo dos estabelecimentos de ensino para o cuidado de crianças com necessidades alimentares especiais constituiu motivo para postergação do ingresso escolar de algumas crianças do presente estudo.

Os profissionais atuantes no ambiente escolar precisam evitar a ingestão e o contato da criança com alimentos com leite de vaca, principal alimento de 
muitas crianças nessa fase, e também lidar com a possibilidade do sentimento de exclusão, fato que preocupa as mães e está relacionado ao bem-estar emocional da criança. Em estudo realizado em Nova York, com 80 crianças com variados tipos de alergia e respectivas famílias, evidenciou-se que o grupo com alergia alimentar apresentou pontuação significativamente maior na Escala Multidimensional de Ansiedade para Crianças, incluindo pontuações mais altas nos índices de rejeição à humilhação e ansiedade social ${ }^{(14)}$.

A carência de apoio e compreensão sobre a gravidade da situação, por parte de pessoas do círculo social da família da criança com alergia à proteína do leite de vaca, pode dificultar ainda mais o tratamento, além de desencadear afastamento e isolamento social da criança e respectiva família ${ }^{(13)}$, especialmente quando esta condição é tratada com descrédito e os cuidados considerados como exagerados, tal como relatado por algumas mães deste estudo, que foram tachadas como demasiadamente cuidadosas ou superprotetoras dos filhos.

O conceito de morfogênese, da Teoria dos Sistemas Familiares, explica esse comportamento. A interferência de fatores externos acarreta mudanças e reconstruções nos sistemas ${ }^{(10)}$. Nesse caso, a incompreensão das pessoas frente a essa condição faz com que as mães evitem o contato e adequem a rotina de todo o núcleo familiar para o alcance de um objetivo - evitar frustações e exposição do filho ao risco de reações $^{(10)}$.

As mães relataram sentir dificuldades em lidar com o fato das crianças com este tipo de alergia, à medida que crescem, sentirem vontade de comer alimentos diferentes. Destarte, com o avançar da idade, as desordens psicossociais nestas crianças são mais frequentes, e estão relacionadas a fatores como ansiedade e bullying ${ }^{(13)}$.

0 receio com relação à contaminação cruzada no processo de produção industrial ou preparo dos alimentos em restaurantes e de não reconhecer a presença de alérgeno nos alimentos foram relatados com frequência, o que corrobora resultado de estudo que identificou que, aproximadamente, $16,0 \%$ das reações alérgicas decorrem de falha na leitura dos rótulos dos alimentos ou contaminação cruzada. Os rótulos dos alimentos precisam conter, em linguagem clara, o indicativo da presença de proteína do leite ${ }^{(15)}$. Destaca-se que a nova resolução da Agência Nacional de Vigilância Sanitária discorre sobre as exigências referentes à rotulagem de alimentos industrializados ${ }^{(16)}$, o que constitui avanço na proteção da saúde de consumidores com alergias alimentares.

Importante evidenciar que mesmo crianças amamentadas exclusivamente com leite materno, dependendo da alimentação da mãe, podem apresentar reações alérgicas às proteínas do leite de vaca e, nestes casos, o diagnóstico é ainda mais difícil ${ }^{(17)}$. Contudo, as alergias alimentares não contraindicam o aleitamento materno, que mundialmente é padrão ouro em nutrição dos lactentes até os seis meses de idade. Na Itália, investigou-se a relação entre aleitamento materno e os níveis de IL-10 (considerado um marcador anti-inflamatório) em 124 crianças acompanhadas em unidade de imunoalergologia, e os resultados indicaram que a amamentação exclusiva induz a hipossensibilização de crianças com dermatite atópica relacionada à APLV, e está associado a menor gravidade ${ }^{(18)}$.

Porquanto, no caso de crianças com alergia à proteína do leite de vaca, a manutenção do aleitamento materno é ainda mais importante, porém exige que a mãe se adeque à rigorosa dieta de exclusão de leite de vaca, derivados e traços. Assim, a nutriz necessita de atenção especial, para que possa se sentir empoderada na manutenção do aleitamento materno. Neste sentido, para assistência integral e humanizada, os profissionais de saúde necessitam considerar as particularidades e a realidade de cada mulher (unidade), em termos biológicos, sociais, psicológicos e culturais, e também das famílias, para assim as compreenderem de forma holística ${ }^{(19-20)}$.

Apesar dos inegáveis benefícios do aleitamento materno, algumas mulheres não conseguem mantê-lo. Isto ocorre por falta de apoio, o que é decorrente do desconhecimento sobre este tipo de alergia, comple- 
xidade da dieta, medo de contaminação e consequentes manifestações alérgicas na criança. Nesses casos, devem ser utilizadas fórmulas hidrolisadas de leite de vaca ou de aminoácidos ${ }^{(3)}$.

As mães deste estudo demonstraram conhecimento em relação à alergia à proteína do leite de vaca, o que provavelmente esteja relacionado ao fato de terem elevada escolaridade, o que lhes permitiu procurar e compartilhar informações e, até mesmo, fornecerem suporte informacional e emocional umas às outras nas redes sociais, que assim configuraram-se como importante rede de apoio. Além disso, pela desinformação por parte de alguns profissionais, os aprendizados conquistados as empoderou e garantiu maior força e segurança frente às incertezas do cuidado.

Neste estudo, por meio da Teoria dos Sistemas Familiares, foi possível apreender tanto como a mãe (unidade) quanto à família (todo) comportam-se frente às vicissitudes ocasionadas pelo adoecimento de um membro. Ficou nítida a readaptação que as unidades (membros) estão dispostas a fazer, como o isolamento social e as mudanças na dieta para o alcance de objetivos em comum, bem-estar e qualidade de vida de todo o sistema.

\section{Conclusão}

A rigorosa restrição alimentar, decorrente da alergia à proteína do leite de vaca, repercute significativamente na vida de crianças e respectivas famílias, em especial das mães, desencadeando isolamento social da família e insegurança quanto à utilização de serviços de saúde e educação, devido ao desconhecimento e despreparo de profissionais.

\section{Colaborações}

Reis P e Nass EMA colaboraram com concepção e projeto, análise e interpretação dos dados e redação do artigo. Batista VC, Marquete VF e Ferreira PC colaboraram na redação do artigo e revisão crítica relevante do conteúdo intelectual. Marcon SS e Ichisato SMT contribuíram com revisão crítica relevante do conteúdo intelectual e aprovação da versão final a ser publicada.

\section{Referências}

1. Aranda CS, Cocco RR, Pierotti FF, Mallozi MC, Franco JM, Porto A, et al. Increased sensitization to several allergens over a 12-year period in Brazilian children. Pediatr Allergy Immunol. 2018; 29(3):321-4. doi: https://doi.org/10.1111/ pai. 12860

2. Ho MH, Wong $\mathrm{WH}$, Chang C. Clinical spectrum of food allergies: a comprehensive review. Clinic Rev Allerg Immunol. 2014; 46(3):225-40. doi: https:// doi.org/10.1007/s12016-012-8339-6

3. Ministério da Saúde (BR). Comissão Nacional de Incorporação de Tecnologias no SUS. Protocolo Clínico e Diretrizes Terapêuticas Alergia à Proteína do Leite de Vaca (APLV) [Internet]. 2017 [citado 2020 jan. 13]. Disponível em: http://conitec.gov.br/images/ Consultas/Relatorios/2017/Relatorio_PCDT_APLV_ CP68_2017.pdf.

4. Flom JD, Sicherer SH. Epidemiology of cow's milk allergy. Nutrients. 2019; 11(5):1051. doi: https://doi. org/10.3390/nu11051051

5. Sociedade Portuguesa de Alergologia e Imunologia Clínica. Alergia alimentar: conceitos, conselhos e precauções. Portugal: Thermo Fisher; 2017.

6. Pensabene L, Salvatore S, D’Auria E, Parisi F, Concolino D, Borrelli 0 , et al. Cow 's milk protein allergy in infancy: a risk factor for functional gastrointestinal disorders in children? Nutrients. 2018; 10(11):1176. doi: https:// doi.org/10.3390/nu10111716

7. Ferreira S, Pinto M, Carvalho P, Gonçalves JP, Lima R, PereiraF.Cow\&smilkproteinallergywithgastrointestinal manifestations. Birth Growth MJ [Internet]. 2014 [cited Jan 13, 2020]; 23(2):72-9. Available from: https:// revistas.rcaap.pt/nascercrescer/article/view/8601

8. Sanchez-Garcia S, Cipriani F, Ricci G. Food allergy in childhood: phenotypes, prevention and treatment. Pediatr Allerg Immunol. 2015; 26(8):711-20. doi: https://doi.org/10.1111/pai.12514

9. Minayo MCS. O desafio do conhecimento: pesquisa qualitativa em saúde. São Paulo: Hucitec; 2016. 
10. Bousso RS. A teoria dos sistemas familiares como referencial para pesquisas com famílias que experienciam a doença e a morte. Rev Min Enferm [Internet]. 2008 [citado 2020 jan. 13]; 12(2):257-61. Disponível em: http:// www.reme.org.br/artigo/detalhes/266

11. Sarinho ESC, Lins MGM. Severe forms of food allergy. J Pediatr. 2017; 93(1):53-9. doi: https:// doi.org/10.1016/j.jpedp.2017.06.009

12. Serpa FS, Cruz AAS, Neto AC, Silva ECF, Franco JM, Mello JML, et al. $\mathrm{O}$ atendimento médico de pacientes com doenças imunoalérgicas no Brasil: reflexões e propostas para a melhoria. Arq Asma Alerg Imunol. 2017; 1(4). doi: http://dx.doi.org/10.5935/2526-5393.20170049

13. Gomes RN, Silva DR, Yonamine GH. Impacto psicossocial e comportamental da alergia alimentar em crianças, adolescentes e seus familiares: uma revisão. Braz J Allergy Immunol. 2018; 2(1):95-100. doi: http://dx.doi. org/10.5935/2526-5393.20180007

14. Goodwin RD, Rodgin S, Goldman R, Rodriguez J, Vos G, Serebrisky D, et al. Food allergy and anxiety and depression among ethnic minority children and their caregivers. J Pediat. 2018; 187:258-264.e1. doi: https:// doi.org/10.1016/j.jpeds.2017.04.055

15. Brum AKR, Fernandes Filha MLFS, Rocha RM, Ferreira SCM. Management of nursing care for children with allergy to cow milk protein. Rev Enferm UFPE online [Internet]. 2016 [cited Dec 21, 2019]; 10(5):4404-7. Available from: https://periodicos.ufpe.br/revistas/ revistaenfermagem/article/view/11191/12745
16. Ministério da Saúde (BR). Agência Nacional de Vigilância Sanitária. Resoluçãon. 26, de 02 julho 2015. Dispõe sobre os requisitos para rotulagem obrigatória dos principais alimentos que causam alergias alimentares [Internet]. 2015 [citado 2019 dez 21]. Disponível em: http:// portal.anvisa.gov.br/documents/10181/2694583/ RDC_26_2015_.pdf/b0a1e89b-e23d-452f-b029a7bea26a698c

17. Rajani PS,MartinH,Groetch M,Javirnen KM.Presentation and management of food allergy in breastfed infants and risks of maternal elimination diets. J Allergy Clin Immunol Pract. 2020; 8(1):52-67. doi: https://doi. org/10.1016/j.jaip.2019.11.007

18. Manti S, Lougaris V, Cuppari C, Tardino L, Dipasquale V, Arrigo T, et al. Breastfeeding and IL-10 levels in children affected by cow's milk protein allergy: a restrospective study. Immunobiology. 2017; 222(2):358-62. doi: http://dx.doi. org/10.1016/j.imbio.2016.09.003

19. Urbanetto PDG, Gomes GC, Costa AR, Nobre CMG, Xavier DM, Silva JG. Guidelines on breastfeeding received by pregnant women during prenatal care. Cienc Cuid Saúde. 2017; 16(4). doi: https://doi.org/10.4025/ cienccuidsaude.v16i4.34071

20. Silva MFFS, Pereira LB, Ferreira TN, Souza AAM. Breastfeeding self-efficacy and interrelated factors. Rev Rene. 2018; 19:e3175. doi: https://doi.org/10.15253/21756783.2018193175
Este é um artigo de acesso aberto distribuído sob os termos da Licença Creative Commons 